\title{
Apoptosis and cell proliferation in porcine placental vascularization
}

\author{
Eva G. Sanchis ${ }^{\mathrm{a}}$, Andrea L. Cristofolini ${ }^{\mathrm{a}}{ }^{\mathrm{b}}$, Mariana R. Fiorimanti ${ }^{\mathrm{a}}$, \\ Claudio G. Barbeito ${ }^{\mathrm{b}, \mathrm{c}, *}$, Cecilia I. Merkis ${ }^{\mathrm{a}}$ \\ ${ }^{a}$ Area of Electron Microscopy, School of Agronomy and Veterinary, National University of Río Cuarto, Route 36 Km 601, Río Cuarto, Argentina \\ b CONICET (National Scientific and Technical Research Council), Argentina \\ ${ }^{\mathrm{c}}$ Laboratory of Descriptive, Comparative and Experimental Histology and Embriology, School of Veterinary Sciences, National University of La Plata, \\ 60 y 118, La Plata, Buenos Aires, Argentina
}

\section{A R T I C L E I N F O}

\section{Keywords:}

\section{Apoptosis}

Pigs

Placenta

Ultrastructure

Vascularization

\begin{abstract}
A B S T R A C T
The placenta is a highly vascularized organ, indispensable tothe transfer of nutrients to the growing fetuses. During gestation, there exists an expansion of the placental vascular network through active angiogenesis. The aim of this research was to study cell proliferation and apoptosis through high resolution light microscopy (HRLM) and transmission electron microscopy (TEM) ultrastructure, immunohistochemistry for Ki67and caspase-3, determination of placental vascular area,and TUNEL assay. Crossbred sows placental tissues from approximately $30 \pm 2(n=5), 40 \pm 2(n=5), 60 \pm 2(n=5), 80 \pm 2(n=5), 90 \pm 2(n=5)$ and $114 \pm 2(n=5)$ days of gestation were used. The evaluation of cell proliferation showed the highest $\%$ Ki67 values on days $30 \pm 2$ and $80 \pm 2$ of pregnancy. Caspase- 3 expressed the highest value on day $30 \pm 2$, while the highest apoptotic indexes were found on days30 \pm 2 and $90 \pm 2$. The placental vascular area was higher on day $80 \pm 2$ of pregnancy. According to our results, an active vascular cell remodeling by a caspase- 3 dependent apoptosis seems to be present in early pregnancy. The increase in the vascular area on day $80 \pm 2$ would be the result of the intense vascular cell proliferation detected with Ki67. Further studies are needed to understand the complex processes of angiogenesis, cell proliferation and apoptosis that interact in the placenta during porcine gestation.
\end{abstract}

\section{Introduction}

Gestation in pigs extends forapproximately 114 days (Hafez and Hafez, 2002). During this period, the placenta plays a vital role in the maintenance of the embryos and fetuses (Wooding and Burton, 2008). The pig placenta is diffuse, rough and epitheliochorial,althoughimportant morphogenetic changes occur in this organ during gestation (Dantzer and Winther, 2001; da Anunciação et al., 2017; Croy et al., 2009)

Placentation includes extensive angiogenesis in maternal and extraembryonic tissues, accompanied by a marked increase in uterine and umbilical blood flow (Goldstein et al., 1980; Biensen et al., 1998; Reynolds and Redmer, 2001; Merkis et al., 2006; Reynolds et al., 2006; Gourvas et al., 2012). The dense networks of blood vessels within the placenta are responsible for exchanging respiratory gases, nutrients and wastes between the mother and the fetus throughout pregnancy, which is essential for proper fetal

\footnotetext{
* Corresponding author at: Laboratory of Descriptive, Comparative and Experimental Histology and Embriology, School of Veterinary Sciences, National University of La Plata, 60 y 118, La Plata, Buenos Aires, Argentina.

E-mail address: barbeito@fcv.unlp.edu.ar (C.G. Barbeito).
} 
growth (Mayhew, 2002; Burton et al., 2009; Sanchis et al., 2015; Pereira et al., 2015). In porcine placenta a remodelation of the placental tissue associated to vascular changes was described by Dantzer and Leiseronly in the initial gestation using corrosion cast technique (Dantzer and Leiser, 1994; Leiser and Dantzer, 1994).

During placental angiogenesis, proliferation of endothelial cells is pivotal to the development of a vascular bed suitable for nutrition of the fetuses. However, the apoptosis, a process that is antagonistic to proliferation, is also necessary for angiogenesis (Troyanovsky et al., 2001).

Together with mitosis, apoptosis controls the number of tissue cells (Heazell et al., 2006; Heazell and Crocker, 2008). Programmed cell death by apoptosis has been linked to the angiogenic process (Troyanovsky et al., 2001). In humans, it has been demonstrated that the endothelial cell apoptosis plays a regulatory role in adult neovascularization (Dimmeler and Zeiler, 2000). Placental angiogenesis has also been indicated as an apoptotic-dependent process, since human placental vessels form and expand due to the intervention of apoptosis (Tertemiz et al., 2005). Moreover, inhibition of endothelial cell apoptosis providing endothelial cell survival has also been indicated as an essential issue during angiogenesis (Zhang et al., 2000; Chavakis and Dimmeler, 2002). Our research group hasmade an attempt to characterize the apoptotic process during placentation in pigs (Cristofolini et al., 2013; Merkis et al., 2010). However, the role of apoptosis and its relation to a proliferativeprocess in porcine placental vascularization is still not completely clear.

Our objective was to evaluate the processes of cell proliferation and apoptosis during the development of the porcine placental vascular network throughout gestation.

\section{Materials and methods}

\subsection{Animals and tissue collection}

The study protocol was approved by the Research Ethics Committee of the National University of Río Cuarto. Reproductive tracts ofcrossbred healthy sows from different slaughterhouses from Río Cuarto city, Argentine $\left(33.11^{\circ} \mathrm{S}\right.$; $\left.64.3^{\circ} \mathrm{O}\right)$ were used. The reproductive tract was obtained immediately after slaughter (approximately on days 30, 40, 60, 80, 90 of gestation) or after delivery (approximately 114 days of gestation), washed with saline solution of Hanks (SSH) containing sodic penicillin G, streptomycine sulphate and fungizone (Gibco, Grand Island, NY, USA), and maintained at $4{ }^{\circ} \mathrm{C}$ until processingwithin 30 min. The uterine horns were opened longitudinally with an incision inthe anti-mesometrial edge. Embryos or fetuses were removed and their gestational age was determined according to the crown-rump length of the litter (Marrable 1971). A total of 30 placentas were selected for the study, including periods from early to term gestation: $30 \pm 2$ days of gestation $(n=5), 40 \pm 2$ days of gestation ( $n=5)$, $60 \pm 2$ days $(n=5), 80 \pm 2$ days $(n=5), 90 \pm 2$ days $(n=5)$ and $114 \pm 2$ days of gestation $(n=5)$.Every period of gestation was selected considering a variation range of approximately 2 days.

Tissue samples were taken from five placentas at every gestational period (one placenta was randomly chosen from each animal). Samples were gathered from the feto-maternal interface and used to determine placental architecture through histological techniques, Ki67 and caspase-3 through immunohistochemistry, and apoptosis through TUNEL.

\subsection{Conventional histological technique}

Portions of approximately $6 \mathrm{~mm}^{3}$ of placental tissue were fixed by immersion in 10 per cent (v/v) buffered-saline formaldehyde pH 7.2-7.4 at $4{ }^{\circ} \mathrm{C}$, dehydrated with alcohol and embedded in paraffin. Then, they were cut in $\pm 4 \mu \mathrm{m}$ histological sections with a microtome (Micron, Germany) and mounted on slides. Paraffin embedded sections were used for immunohistochemistry, TUNEL assay and vessel determination. Previous to analyses, the sections were rehydrated with alcohol and washed with distilled water and PBS.

\subsection{High resolution light microscopy}

For high resolution light microscopy (HRLM), portions of approximately $1 \mathrm{~mm}^{3}$ of placental tissue were processed by conventional transmission electron microscopy technique. Placental samples were fixed in $2.5 \%$ glutaraldehyde in $0.2 \mathrm{M} \mathrm{S-collidine} \mathrm{pH} \mathrm{7.4,}$ post-fixed in $1 \%$ osmium tetroxide in $0.2 \mathrm{M} \mathrm{S}$-collidine $\mathrm{pH} 7.4$, dehydrated in increasing concentration acetone, embedded in EMbed 812 resin and sectioned with an ultramicrotome to obtain semi-thin sections $( \pm 0.25 \mu \mathrm{m})$. These sections were counterstained with toluidinés blue and were cover-slipped in DPX (Merk, Germany) embedding agent. They were then observed in a light microscope Axiophot (Carl Zeiss, Germany) fitted with a high resolution digital camera Powershot G6 7.1 megapixels (Canon INC, Japan). Digital images were captured with Axiovision 4.6.3 software (Carl Zeiss, Germany).

\subsection{Transmission electron microscopy}

Ultra-thin sections ( $\pm 60 \mathrm{~nm}$ ) were cut with an ultramicrotome from resin embedded tissues. They were placed on cupper grids, counterstained with saturated uranyl acetate and aqueous lead citrate. The sections were examined with a transmission electron microscope Elmiskop 101 (Siemens, Germany).Acquisition, digital analysis and morphometric measurements were performed with transmission electron microscope JEM 1200 ExII (JEOL, Japan), using aDigital MicrographTM (Gatan, Inc., Japan) software. The reagents employed were from Electron Microscopy Science. 


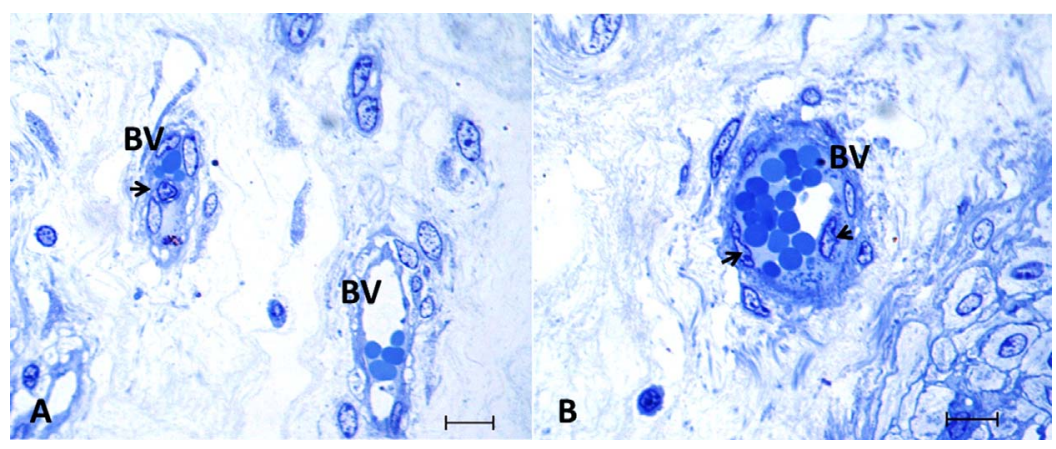

Fig. 1. Semi-thin sections of porcine placenta collected at \pm 30 days of gestation. Apoptosis characterized by marked chromatin condensation is seen in endothelial cells of placental vessels (arrows). 1000X. In all panels, scale bar: $10 \mu \mathrm{m}$. BV: placental blood vessels.

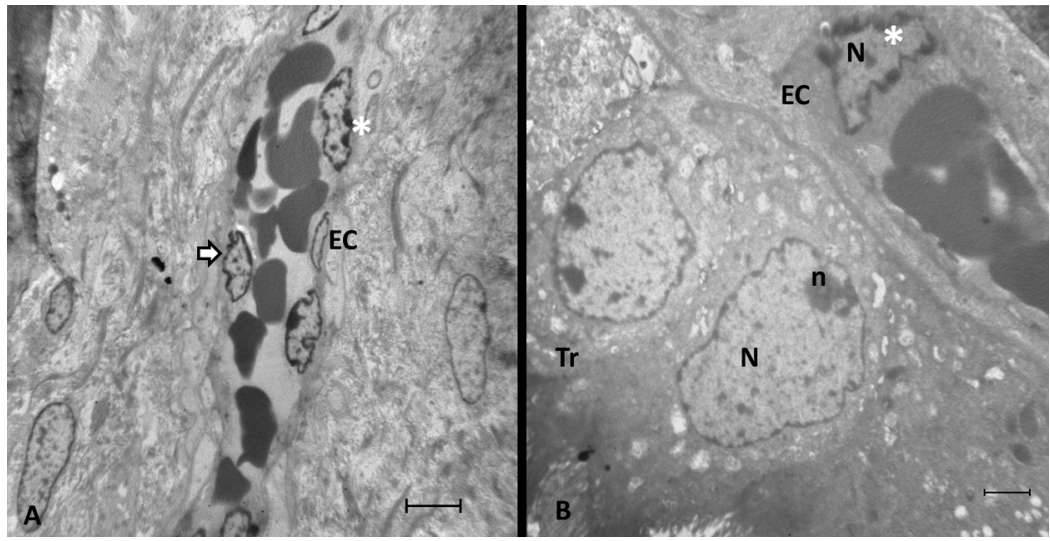

Fig. 2. Transmission electron micrographs of porcine placenta from \pm 30 days of gestation. Endothelial cells (EC) show features of differentiation coincident with the apoptotic process, with irregularity in nuclear shape. Nuclei show thin (arrow) and dense (white asterisk) rim of peripherally located heterochromatin and dispersed euchromatin. A: 4000x, scale bar: $5 \mu \mathrm{m}$. B: $8000 \mathrm{x}$, scale bar: $2 \mu \mathrm{m}$. Tr: trophoblastic cell; N: nucleus; n: nucleolus.

\subsection{Immunohistochemistry}

Washed sections obtained from the conventional histological technique were kept in $3 \% \mathrm{H}_{2} \mathrm{O}_{2}$ for 20 min to remove endogenous peroxidase activity, followed by three washes with PBS. After blocking with $5 \%$ normal horse serum to reduce nonspecific binding, sections were incubated for $1 \mathrm{~h}$ with primary antibodies, as we have previously described (Sanchis et al., 2011): mouse monoclonal anti-human Ki67 antibody, working dilution 1/100 (DakoCytomation, USA; clone MIB 1, code M-7240), ) and rabbit polyclonal antipig caspase-3 antibody, working dilution 1/100 (Santa Cruz Biotechnology, Inc, USA; code sc-7272). Tissues were rinsed twice in PBS and then incubated for $20 \mathrm{~min}$ with biotinylated secondary antibodies pool and $20 \mathrm{~min}$ with streptavidin conjugated to horseradish peroxidase (LSAB ${ }^{\circ}+$ Systems HRP, DakoCytomation, USA). After two washes in PBS, the antibody binding was stained for 10 min using 3,3'-diaminobenzidine chromogen solution (Liquid DAB + SubstrateChromogen System, DakoCytomation). The sections were counterstained with Mayeŕs haematoxylin, washed, dehydrated and cover-slipped in Entellan (Merk, Alemania) embedding agent. Negative controls included omission of the primary antibody. All sections were stained immunohistochemically under the same conditions and at room temperature. Photomicrographs were evaluated with an Axiophot microscope (Carl Zeiss, Germany) fitted usinga high resolution digital camera Powershot G6 7.1 megapixels (Canon Inc, Japan). Digital images were captured with Axiovision 4.6.3 software.

The evaluation for Ki67 was recorded as percentages of labelled endothelial and perivascular cells. Values of $\%$ Ki67 were obtained by randomly enumerating Ki67 positive cells from 10 fields at a magnification of 1000 times and expressed as percentages of positive cells. In each field, Ki67 positive and total endothelial and perivascular cells were counted. Maternal and fetal components were analyzed together and separately. Two observers performed the percentage evaluations and the average score was used.

$\%$ Ki67 = Ki67 positive cells/Total cells * 100.

For each immune-stainedtissuewith caspase-3 a High Score (HSCORE) value was used. The HSCORE wasderived by addingthe percentages of placental tissuestained at each intensity level and multiplying that by the weighted intensity of the staining (Selam et al., 2011) as follow:

$$
\text { HSCORE }=\Sigma \mathrm{Pi}(\mathrm{i}+1)
$$



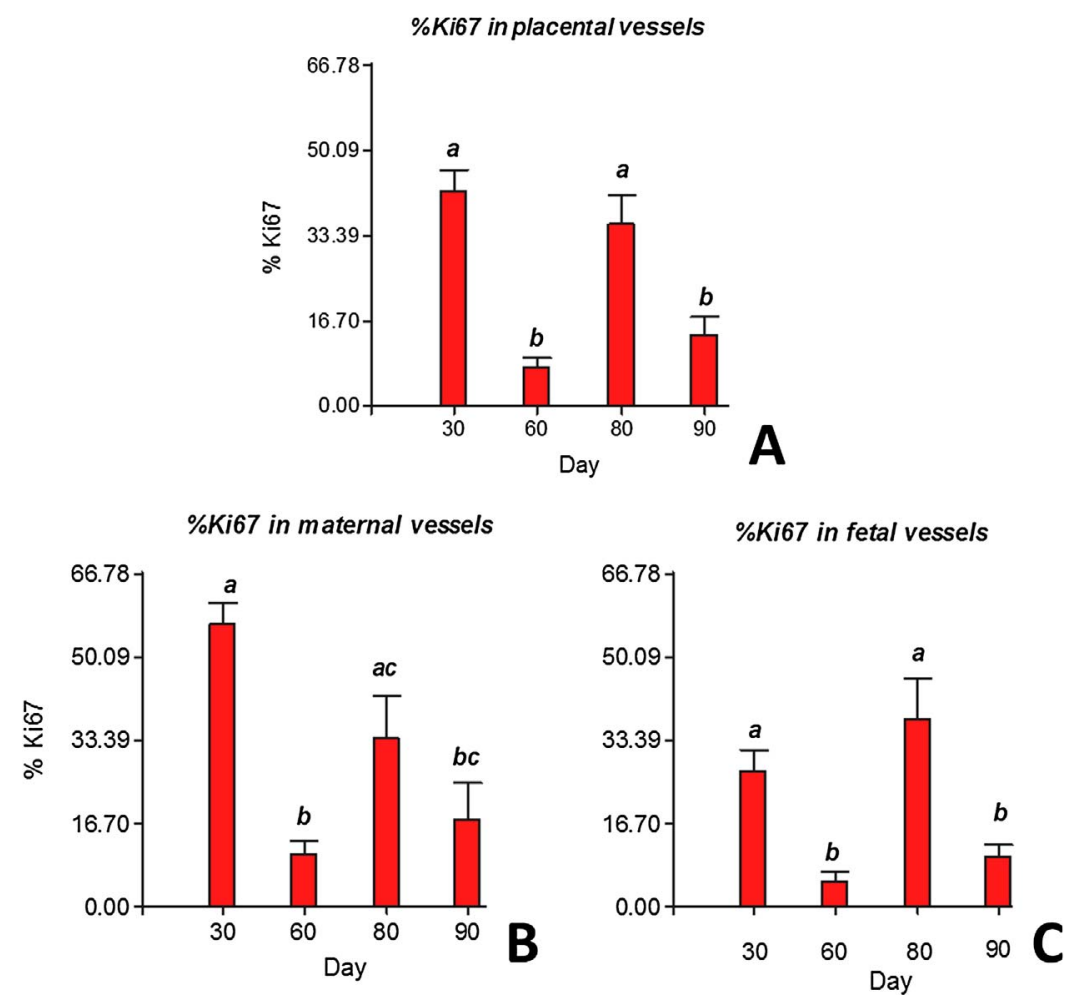

Fig. 3. Distribution of Ki67 immunostaining intensity in porcine placental tissues according to day of gestation. Staining intensity was significantly higher at \pm 30 and \pm 80 days of gestation in total and fetal vessels $(\mathrm{p} \leq 0.05)$.

Where i represents the intensity scores and $\mathrm{Pi}$ is the corresponding percentage of cells. Five randomly selected areas per slide were evaluated under a light microscope with a 100x magnification; the values were determined by two investigators at different times, and the average score was used.

\subsection{TUNELassay}

Paraffin-embedded tissues from approximately $30 \pm 2,60 \pm 2,80 \pm 2,90 \pm 2$ and $114 \pm 2$ days of gestation were used for TUNEL technique to determine the apoptotic vascular cells in porcine placental tissues. Nuclei DNA fragmentation was detected in situ using the terminal deoxynucleotidyltransferase (TdT)-mediated dUTP nick end labelling (TUNEL) method (ApopTag ${ }^{\circledR}$ Plus Peroxidase In Situ Apoptosis, Chemicon International, USA). The analysis was conducted as described in the kit protocol, following the recommendation of a pre-treatment of slides with Triton X-100, as suggested by the manufacturer.

The results were expressed as quantitative. The apoptotic index (IAp) for the different periods of gestation was calculated withthe following formula:

$$
\text { IAp }=\text { TUNEL positive cells/Total cells } \times 100
$$

The quantification was carried out by a single operator on two slides per animal/placenta and five fields per slide at a magnification of 1000 times. In each field, total and TUNEL positive endothelial and perivascular cells were counted.

\subsection{Statistical analysis}

Data from immunohistochemistry and TUNEL technique were analyzed with InfoStat Version 2009 software (Di Rienzo et al., 2009). Dependence of \%Ki67, TUNEL and vascular area on the gestational period were also analyzed. When a parametric ANOVA test could not be performed, even with variable transformations, a nonparametric ANOVA by ranks (Kruskal-Wallis test) was used. According to this, a nonparametric test was used for Ki67, TUNEL from maternal vessels and caspase-3 determinations.

\section{Results}

\subsection{Vascular placental ultrastructure}

The study of ultrastructure by HRLM and TEM shows the presence of endothelial and perivascular apoptotic cells in placental 


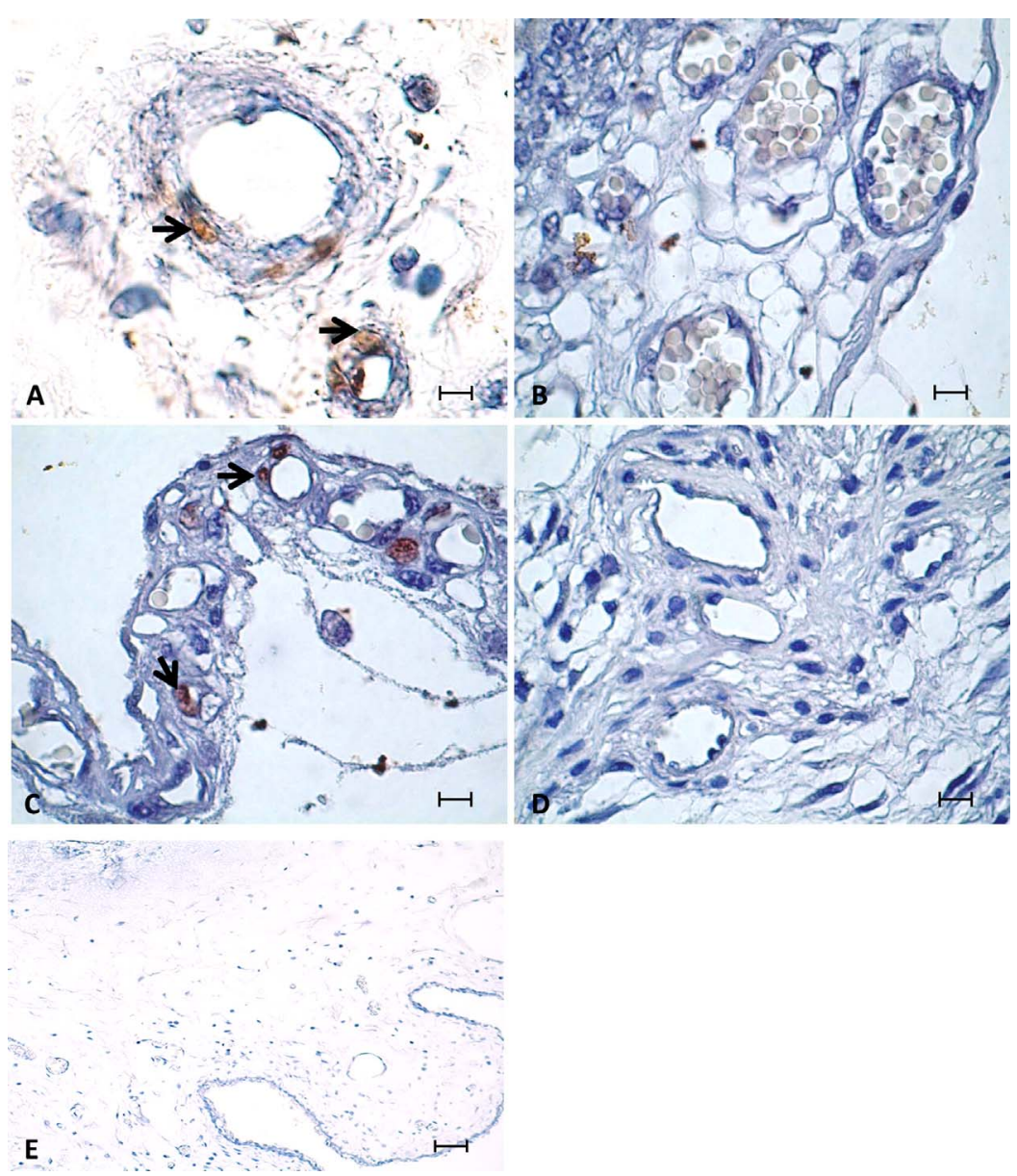

Fig. 4. Immunohistochemical staining of Ki67. Representative micrograph of staining of Ki67 (black arrows) in the nuclei of porcine placental endothelial cells from healthy gilts of A) $\pm 30, \mathrm{~B}) \pm 60, \mathrm{C}) \pm 80$, D) \pm 90 days of gestation. A) and C) correspond to fetal placental tissues; B) and D) belongs to maternal placental tissues. E) negative control for Ki67 in porcine placenta of 30 days of gestation; no staining is observed. A, B, C and D: $1000 x$, scale bar: $5 \mu \mathrm{m}$. E: $10 \mathrm{x}$, scale bar: $50 \mu \mathrm{m}$.

High Score caspase-3

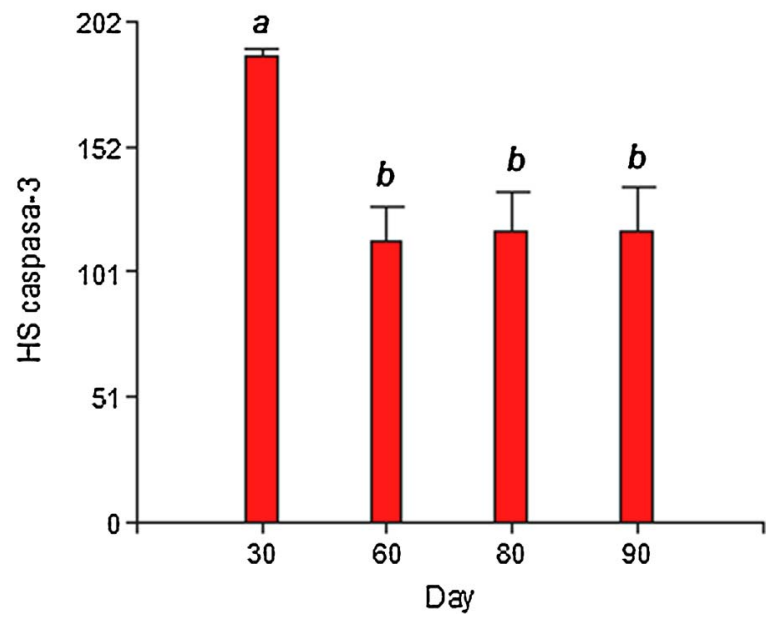

Fig. 5. Distribution of caspase- 3 in porcine placental tissues according to day of gestation. Staining intensity of placenta was significantly higher at day \pm 30 of gestation compared with the rest of the periods evaluated $(\mathrm{p} \leq 0.05)$. 


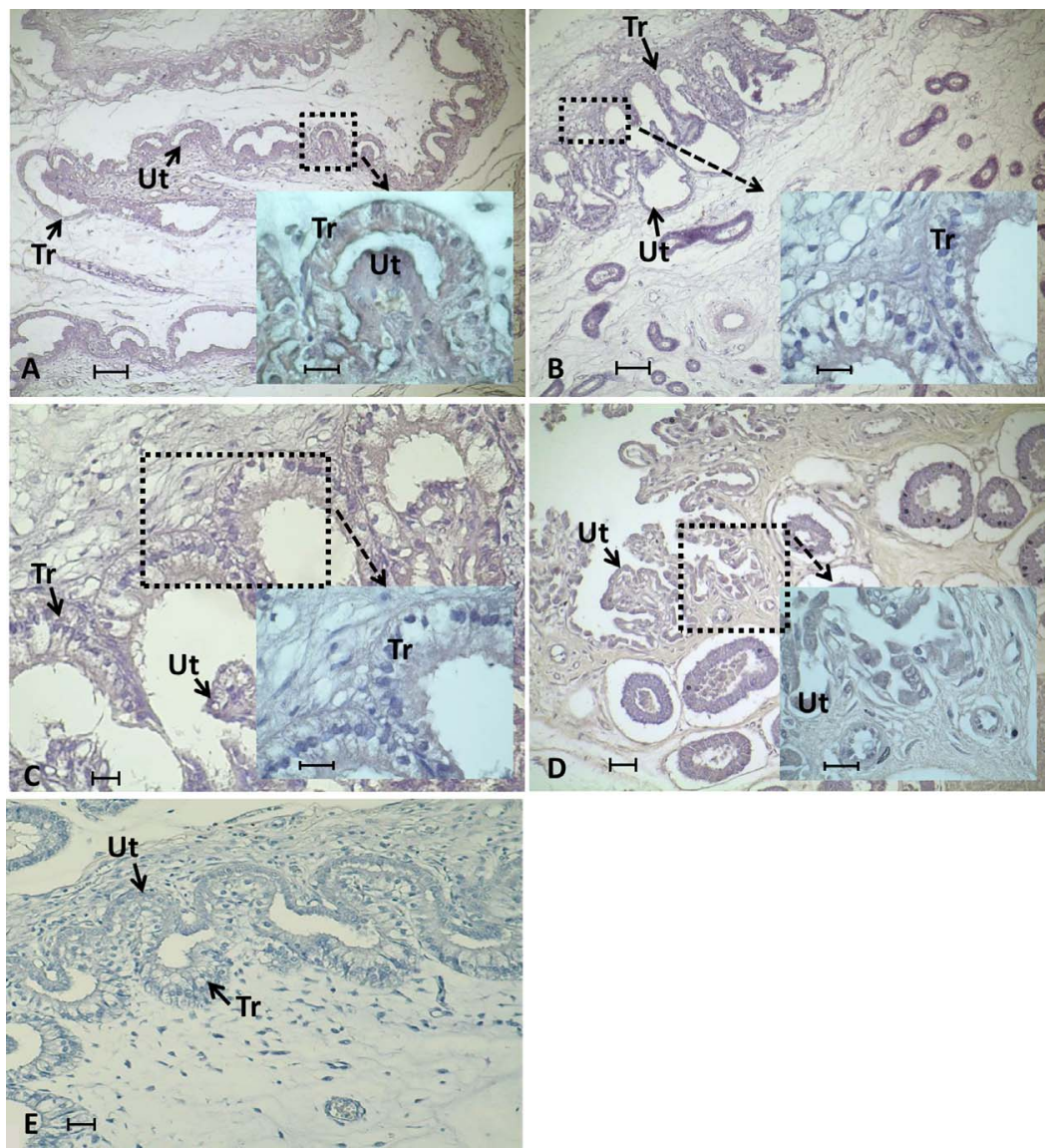

Fig. 6. Immunohistochemistry of caspase-3 in porcine placental tissues from A) \pm 30 days of gestation; B) \pm 60 days; C) \pm 80 days; D) \pm 90 days; E: negative control, no staining is observed. Higher caspase- 3 immunostaining was observed in magnification of A. A and B: $100 x$, scale bar: $50 \mu \mathrm{m}$. C and E: $400 x$, scale bar: $10 \mu \mathrm{m}$. D: 200x, scale bar: $20 \mu \mathrm{m}$. Insets: 1000x, scale bar: $5 \mu \mathrm{m}$. Tr: trophoblast; Ut: uterine epithelium.

blood vessels (Figs. 1 and 2). Typical morphology of apoptosis with condensed nuclear heterochromatin, reduced cell volume, loss of contact with neighboring cells and formation of apoptotic bodies isfoundin some vessels, while other vessels seem to be present in early stages of the programmed cell death (Fig. 2).

\subsection{Determination of Ki67 in placental vessels}

An effect of the day of gestation on the \%Ki67 index of total blood vessels was detected $(\mathrm{P}=0.0001)$. The highest values were found on days30 $\pm 2(42.01)$ and $80 \pm 2$ (35.71) of gestation $(\mathrm{P} \leq 0.05)$. Fetal and maternal blood vessels also expressed the highest values of \%Ki67 on days $30 \pm 2$ (56.88 maternal, 27.14 fetal) and $80 \pm 2$ (33.94 maternal, 37.48 fetal) (Fig. 3). Representative images of days $30 \pm 2$ and $80 \pm 2$ of gestation show positive nuclei for Ki67 in vascular cells (Fig. 4a,c).Very few positive vessel cells for Ki67 are seen on images from days $60 \pm 2$ and $90 \pm 2$ of gestation (Fig. 4b,d).

\subsection{Caspase-3 immunohistochemistry}

Dependence of day of gestation on caspase- 3 immunohistochemistry was found $(\mathrm{P}=0.004)$, with the highest value on day $30 \pm 2$ and no difference among the remaining periods $(\mathrm{P} \leq 0.05$ ) (Fig. 5). Low expression of caspase-3 was detected in every gestational period evaluated, in fetal mesenchyme and stroma (Fig. 6).

\subsection{TUNEL index in placental vessels}

An effect of the day of gestation on the IAp of total blood vessels was detected $(\mathrm{P}=0.0004)$. The highest IAp was found on day $90 \pm 2$ (64.31) $(\mathrm{P} \leq 0.05)$. IAp of maternal blood vessels was also influenced by the day of gestation $(\mathrm{P}=0.001)$ with the highest values on days $30 \pm 2$ (66.63) and $90 \pm 2$ (62.88), and the lowest on60 \pm 2 (35.55) and $80 \pm 2$ (39.34) days of pregnancy $(\mathrm{P} \leq 0.05)$ (Fig. 7). The apoptotic index of fetal blood vessels was not influenced by the day of gestation $(\mathrm{P}=0.06)$.TUNEL positive nuclei, presumably apoptotic, were seen in cells of placental vessels in every period of gestation evaluated. In Fig. 8a, a representative 

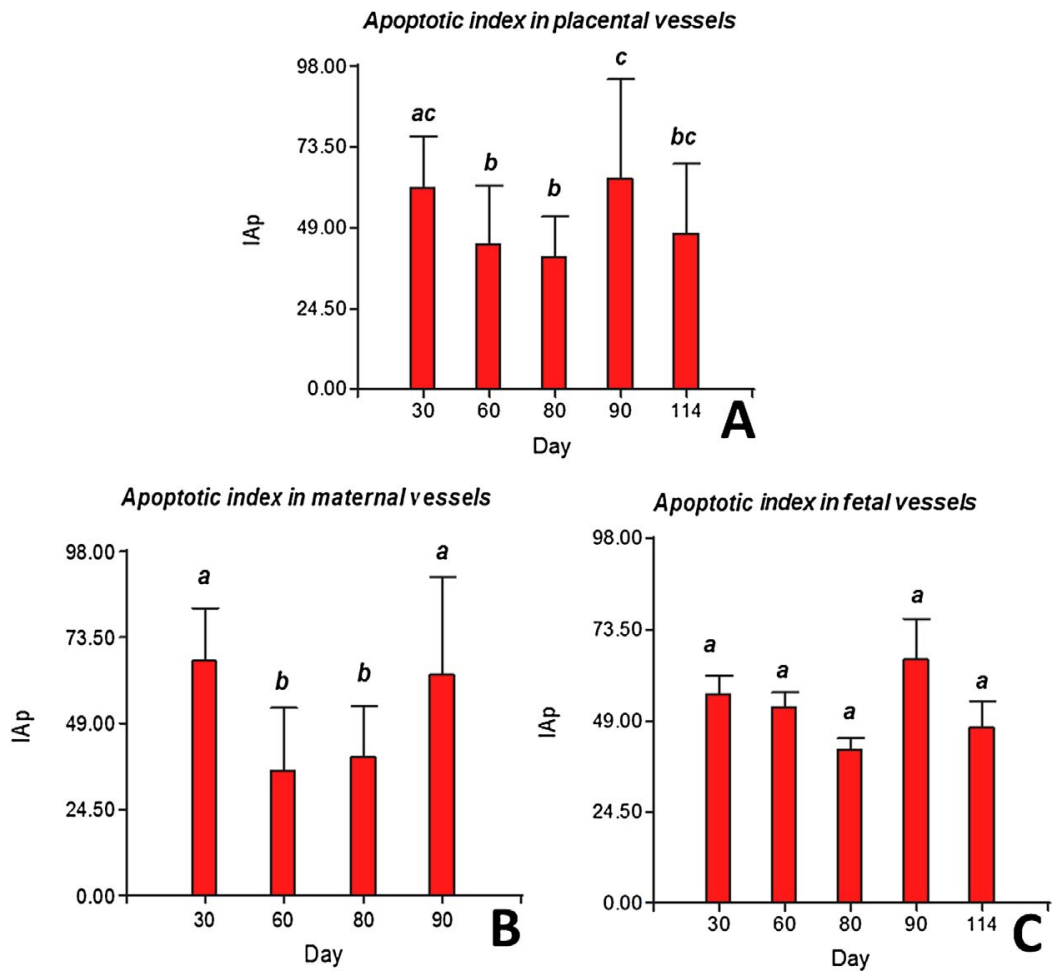

Fig. 7. Distribution of apoptotic index in porcine placental tissues according to day of gestation. Staining intensity was significantly higher at \pm 30 and \pm 80 days of gestation in total and fetal vessels $(\mathrm{p} \leq 0.05)$

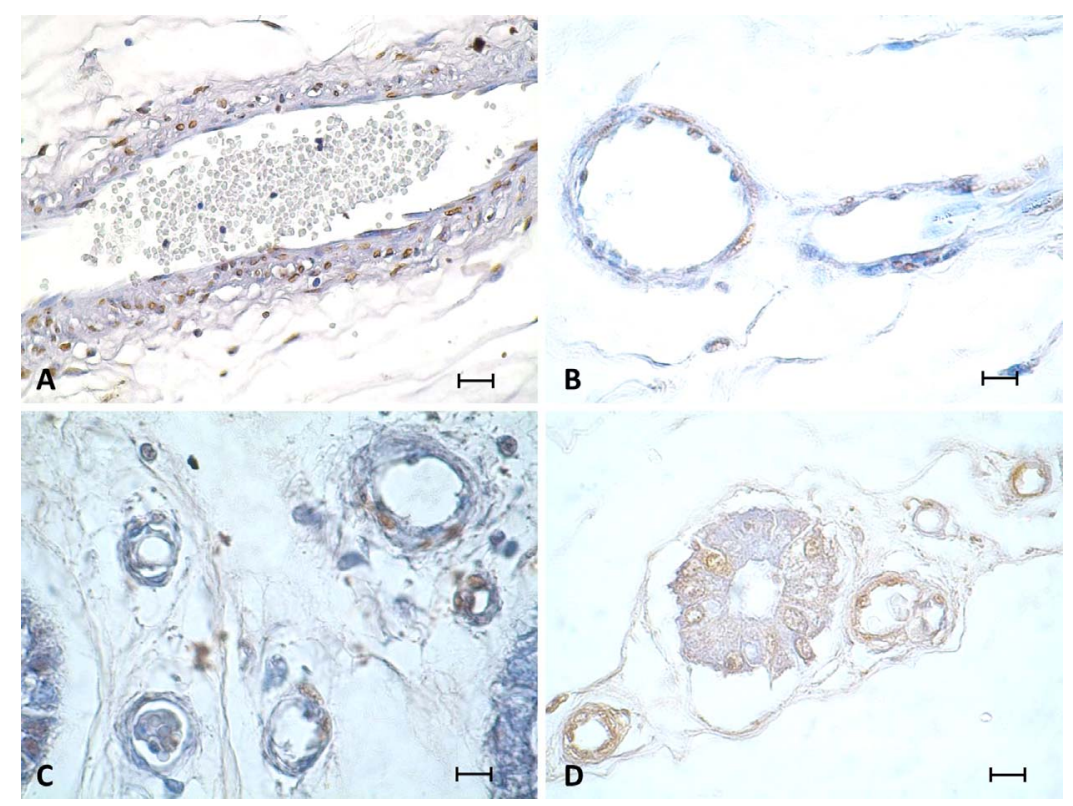

Fig. 8. Detection of TUNEL positive nuclei (brown) in porcine placental vascular cells of A) 30, B) 60, C) 80 and D) 90 days of gestation. A) and D) correspond to maternal placental tissues; B) and C) belongs to fetal placental tissues. In Aa representative maternal vessel shows multiple brown nuclei in endothelial and perivascular cells. In B-D show TUNEL positive endothelial nuclei from fetal and maternal vessels. In all panels: 1000x, scale bar: $5 \mu \mathrm{m}$. 
maternal vessel from $30 \pm 2$ days shows multiple brown nuclei in endothelial and perivascular cells. Fig. 8b-d show TUNEL positive endothelial nuclei from fetal and maternal vessels.

\section{Discussion}

The relevance of vascular development to placental function has been widely discussed (Reynolds and Redmer, 2001; Mayhew, 2002; Merkiset al., 2006; Burton et al., 2009) since it influences fetal development and growth (Gourvas et al., 2012; Pereira et al., 2015) Conceptus loss, associated with a disruption of the embryonic growth, in the early and middle gestation of domestic pigs, is considerate one of the most important problems of the porcine production (Kridli et al., 2016). Changes in angiogenesis in the placenta is the most import factor related to the disruption of the embryonic growth (Linton et al., 2008)

Diverse changes were found in the porcine placenta along its development. The chorioalantoic folds increase between 25-50 gestational days. This increase is related to generate a big surface to exchange (Liu et al., 2015). In concordance, our results show a significant increase in the vascular area in porcine placental tissues up to day 80 of pregnancy (no published data). This increase in the vascular area coincides with the augmentation of proliferating vascular cells demonstrated by Ki67, which finds its highest values in this period of gestation. Previous studies suggest that the expansion of the vascular area results from the augmentation of large vessels (Merkis et al., 2006). This is in agreement with the studies carried outby Biensen et al. (1998), who found that between days 70 and 90 of pregnancy there is a period of fast vascular placental cell proliferation in Meishansows. Moreover, the development of the vascular area is related to the growing metabolic demands of the concepti that occur in pigs from day 50 of gestation on wards (Goldstein et al., 1980).

High apoptotic levels were found in placental blood vessels during early gestation. This is indicative of an active vascular remodeling by apoptosis, favoring the angiogenic process.This conclusion also emerges from the observation of HRLM and TEM,where some endothelial cells seem to have apoptotic features. Several studies have suggested that high numbers of endothelial apoptotic cells inhibit angiogenesis (Dimmeler and Zeiher, 2000; Zhang et al., 2000; Troyanovsky et al., 2001). However, our results suggest that apoptosis in normal pig placenta has positive effects on angiogenesis. Similar findings were previously made in humans (Tertemiz et al., 2005).In the present study, the detection of caspases in the placenta along with gestation suggests a caspasedependent apoptosis process. Future experiments are necessary to dilucidate more throughing the apoptotic patway implicated in the endothelial apoptosis in porcine pig. Recently studies highlight the importance of the extinsec apoptotic via mediated by Tumor necrosis factor-related apoptosis-inducing ligand (TRAIL) and its receptor, death receptor 4 (DR4). They have been implicated in the development of endothelial death in other localizations as liver sinusoids (Badmann et al., 2012) and coronary arteries (Li et al., 2013). In placental vessels the rol of TRAIL was found in the muscle cells of spiral artery in human haemochorial placenta (Keogh et al., 2007) and was associated with recurrent miscarriage (Rull et al., 2013) The importance of TRIAL was not studied in epitheliochorial placenta. However, the absence of significative differences in the apoptosis index along pregnancy could be demonstrate an independence of placental cytokines that changes between Th1 to a Th2 profile during pregnancy (Wesselset al., 2007), with a great importance of proinflammatory cytokines in the early pregnancy (Geisert et al., 2014).

The proliferation of vascular cells accompanied by an apoptosis dependent remodeling process observed in this study is in agreementwith the informationprovided by Mayhew (2002). His studies in human placenta show a continuous proliferation as gestation advances followed by an active remodeling of vascular endothelial cells. In porcine placenta the expression of VEGF and their receptors show differences during gestation (Winther et al., 1999; Sanchis et al., 2015). In a previous paper of our group demonstrate that VEGF levels decrease in pig placenta in the 80 day (Sanchis et al., 2015). The increase of vascular cell proliferation in this day, found in the present paper, could be related to other angiogenic factors. Edwards et al. (2011) demonstrate the expression of other angiogenic factors as FGF-2 and PDGF but only studied placenta of 20 and 50 gestational days. The potential importance of this factor in the increase of vascular proliferation in more advanced placenta development must be analysed in further works.

Our results help to understand the complex process of gestation that involves several events as angiogenesis, cell proliferation and apoptosis. What is more, it seems that an adequate balance between apoptosis and cell proliferation is necessary to maintain a stable population of placental vessels.

\section{Conflict of interest}

The authors report no conflicts of interest. The authors alone are responsible for the content and writing of this paper.

\section{Acknowledgments}

We would like to express our gratitude to Mrs. NelcySchleef for her excellent technical assistance. This work has been partially supported by SeCyT UNRC and PID075/2010MinCyT Córdoba Argentina.. We would also like to acknowledge CONICET (National Scientific and Technical Research Council) Argentina. for itsfinancial support.

\section{References}

Badmann, A., Langsch, S., Keogh, A., Brunner, T., Kaufmann, T., Corazza, N., 2012. TRAIL enhances paracetamol-induced liver sinusoidal endothelial cell death in a Bim- and Bid-dependent manner. Cell Death Dis. 20 (December (3)). http://dx.doi.org/10.1038/cddis.2012.185.

Biensen, N., Wilson, M., Ford, S., 1998. The impact of either a Meishan or a Yorkshire uterus on Meishan or a Yorkshire fetal and placental development to days 70, 90 
and 110 of gestation. J. Anim. Sci. 76, 2169-2176.

Burton, G., Charnock-Jones, D., Jauniaux, E., 2009. Regulation of vascular growth and function in the human placenta. Reproduction 138, 895-902.

Chavakis, E., Dimmeler, S., 2002. Regulation of endothelial cell survival and apoptosis during angiogenesis. Arterioscler. Thromb. Vasc. Biol. 22 , 887-893.

Cristofolini, A., Sanchis, G., Moliva, M., Alonso, L., Chanique, A., Koncurat, M., Merkis, C., 2013. Cellular remodelling by apoptosis during porcine placentation. Reprod. Dom. Anim. 48, 584-590.

Croy, B.A., Wessels, J.M., Linton, N.F., van den Heuvel, M., Edwards, A.K., Tayade, C., 2009. Cellular and molecular events in early and mid gestation porcine implantationsites: a review. Soc. Reprod. Fertil. Suppl. 66, 233-244.

da Anunciação, A., Mess, A.M., Orechio, D., Aguia, r B.A., Favaron, P.O., Miglino, M.A., 2017. Extracellular matrix in epitheliochorial, endotheliochorial and haemochorialplacentation and its potential application for regenerative medicine. Reprod. Domest. Anim. 52, 3-15.

Dantzer, V., Leiser, R., 1994. Initial vascularisation in the pig placenta: I. Demonstration of nonglandular areas by histology and corrosion casts. Anat. Rec. 238, 177-190.

Dantzer, V., Winther, H., 2001. Histological and immunohistochemical events duringplacentation in pigs. Reprod 58, 209-222 Suppl.

Di Rienzo, J., Casanoves, F., Balzarini, M., Gonzalez, L., Tablada, M., Robledo, C., 2009. InfoStat Versión 2009 Grupo InfoStat, FCA. Universidad Nacional de Córdoba, Argentina.

Dimmeler, S., Zeiher, A., 2000. Endothelialcell apoptosis in angiogenesis andvesselregression. Circ. Res. 87, 434-439.

Edwards, A.K., den Heuvel, M.J., Wessels, J.M., LaMarre, J., Croy, A.B., Tayade, C., 2011. Expression of angiogenic basic fibroblast growth factor, platelet derived growth factor, thrombospondin-1 and their receptors at the porcine maternal-fetal interface. Reprod. Biol. Endocrinol. 9, 5.

Geisert, R.D., Lucy, M.C., Whyte, J.J., Ross, J.W., Mathew, D.J., 2014. Cytokines from the pigconceptus: roles in conceptus development in pigs. J. Anim. Sci. Biotechnol. 5, 51. http://dx.doi.org/10.1186/2049-1891-5-51.

Goldstein, M., Bazer, F., Barron, D., 1980. Characterization of changes in volume, osmolarity and electrolyte composition of porcine fetal fluids during gestation. Biol. Reprod. 22, 1168-1180.

Gourvas, V., Dalpa, E., Konstantinidou, A., Vrachnis, N., Spandidos, D.A., Sifakis, S., 2012. Angiogenic factors in placentas from pregnancies complicated by fetal growth restriction (Review). Mol. Med. Rep. 6, 23-27.

Hafez, E., Hafez, B., 2002. Reproducción e inseminación artificial en animales, 7th ed. McGraw-Hill.

Heazell, A., Crocker, I., 2008. Live and Let Die Regulation of villous trophoblast apoptosis in normal and abnormal pregnancies. Placenta 29, 772-783.

Heazell, A., Harris, L., Forbes, K., Crocker, I., 2006. Placental cell turnover in health and disease. Rev. Gyn. Perin. Pract. 6, 80-86.

Keogh, R.J., Harris, L.K., Freeman, A., Baker, P.N., Aplin, J.D., Whitley, G.S., Cartwright, J.E., 2007. Fetal-derived trophoblast use the apoptotic cytokine tumor necrosis factor-alpha-related apoptosis-inducing ligand to induce smooth muscle cell death. Circ. Res. 100, 834-841.

Kridli, R.T., Khalaj, K., Bidarimath, M., Tayade, C., 2016. Placentation, maternal-fetalinterface, and conceptus loss in swine. Theriogenology 85, $135-144$.

Leiser, R., Dantzer, V., 1994. Initial vascularisation in the pig placenta: II. Demonstration of gland and areola-gland subunits by histology and corrosioncasts. Anat. Rec. 238, 326-334.

Li, X., Han, W.Q., Boini, K.M., Xia, M., Zhang, Y., Li, P.L., 2013. TRAIL death receptor 4 signaling via lysosome fusion and membrane raft clustering in coronary arterial endothelial cells: evidence from ASM knockout mice. J. Mol. Med. 91, 25-36.

Linton, N.F., Wessels, J., Cnossen, S., Croy, B., Tayade, C., 2008. Immunological mechanims affecting angiogenesis and relation to porcine pregnancy success. Immunol. Invest. 37, 611-629.

Liu, R., Wang, M., Su, L., Li, X., Zhao, S., Yu, M., 2015. he expression pattern of microRNAs and the associated pathways involved in the development of porcine placental folds that contribute to the expansion of the exchange surface area. Biol. Reprod. 93 (62). http://dx.doi.org/10.1095/biolreprod.114.126540.

Marrable, A., 1971. The Embryonic Pig: A Chronological Account. Exeter Pitman Medical, London.

Mayhew, T., 2002. Fetoplacental angiogenesis during gestation is biphasic, longitudinal and occurs by proliferation and remodeling of vascular endothelial cells. Placenta 23, 742-750.

Merkis, C., Cristofolini, A., Franchino, M., Sanchis, E., Moschetti, E., Koncurat, M., 2006. Angiogenesis placentaria durante la gestación porcina. REDVET 7, 1-4.

Merkis, C., Cristofolini, A., Sanchis, E., Koncurat, M., 2010. Expression of death cellular receptors FAS/CD95 and DR4 during porcine placentation. Int. J. Morphol. 28, 829-834.

Pereira, R.D., De Long, N.E., Wang, R.C., Yazdi, F.T., Holloway, A.C., Raha, S., 2015. Angiogenesis in the placenta: the role of reactive oxygen species signaling. Biomed. Res. Int. 1-12. http://dx.doi.org/10.1155/2015/814543.

Reynolds, L., Redmer, D., 2001. Angiogenesis in the placenta. Biol. Reprod. 64, 1033-1040.

Reynolds, L., Caton, J., Redmer, D., Grazul-Bilska, A., Vonnahme, K., Borowicz, P., Luther, J., Wallace, J., Wu, G., Spencer, T., 2006. Evidence for altered placental blood flow and vascularity in compromised pregnancies. J. Physiol. 572, 51-58.

Rull, K., Tomberg, K., Kõks, S., Männik, J., Möls, M., Sirotkina, M., Värv, S., Laan, M., 2013. Increased placental expression and maternal serum levels of apoptosisinducing TRAIL in recurrent miscarriage. Placenta 34, 141-148.

Sanchis, G., Cristofolini, A., Taglialegna, A., Merkis, C., 2011. Porcine uterine extracellular matrix molecules throughout pregnancy. Int. J. Morphol. 29, 1438-1443.

Sanchis, E.G., Cristofolini, A., Merkis, C., 2015. Porcine placentalimmunoexpression of vascular endothelial growth factor placenta growth factor, Flt-1 andFlk-1. Biotech. Histochem. 90, 486-494.

Selam, B., Kayisli, U., Mulayim, N., Arici, A., 2011. Regulation of fas ligand expression by estradiol and progesteronein human endometrium. Biol. Reprod. 65, 979-985.

Tertemiz, F., Kayisli, U.A., Arici, A., Demir, R., 2005. Apoptosis contributes to vascular lumen formation and vascular branching in human placental vasculogenesis. Biol. Reprod. 72, 727-735.

Troyanovsky, B., Levchenko, T., Mansson, G., Matvijenko, O., Holmgren, L., 2001. Angiomotin: an angiostatin-binding protein that regulates endothelial cell migration and tube formation. J. Cell. Biol. 152, 1247-1254.

Wessels, J.M., Linton, N.F., Croy, B.A., Tayade, C., 2007. A review of molecular contrasts between arresting and viable porcine attachment sites. Am. J. Reprod. Immunol. 58, 470-480.

Winther, H., Amhed, A., Dantzer, V., 1999. Inmunohistochemical localization of Vascular Endothelial Growth Factor (VEGF) and its two specific receptors Flt-1 and $\mathrm{KDR}$, in the porcine placenta and non-pregnant uterus. Placenta 20, 35-43.

Wooding, P., Burton, G., 2008. Comparative Placentation: Structures, Functions and Evolution. Springer-Verlag, Berlín Heidelberg.

Zhang, J., Claffey, K., Sakthivel, R., Darzynkiewicz, Z., Shaw, D., Leal, J., Wang, Y., Lu, F., McCrae, K., 2000. Two-chain high-molecular-weight kininogen induces endothelial cell apoptosis and inhibits angiogenesis: partial activity within domain 5. FASEB J. 14, 2589-2600. 